\title{
An Empirical Research on Influence Factor of College Students' Continued Intentions of Online Self-Regulated Learning Based on the Model of ECM and TAM
}

\author{
Luo Yumei \\ College of Business management and Tour management \\ Yunnan University, Kunming, China
}

\author{
Ye Qiongwei* \\ Business School \\ Yunnan University of Finance and Economics \\ Kunming, China \\ Corresponding author : yeqiongwei@163.com
}

\author{
Meng Luoyan \\ College of Business management and Tour management \\ Yunnan University, Kunming, China
}

\begin{abstract}
Online self-regulated learning has been concerned as one of important learning method. The value of online selfregulated learning can be realized by sustained and effective usage, so it is more important to explore the influence factor of college students' continued intentions of online self-regulated learning. Based on the Expectation Confirmation Model and Technology Acceptance Model, this paper proposes a conceptual model of explaining the continued intention of online selfregulated learning. Using the data from college students and the Partial Least Squares (PLS) method, the paper explores the key elements and mechanisms that impact the continued intention of online self-regulated learning. There are several findings: Firstly, the perceived usefulness, attitude and using satisfaction positively influence continued learning intention, and the perceived usefulness impacts indirectly continued intention through satisfaction and attitude. Secondly, college students' satisfaction has a significant and direct impact on the attitude of online selfregulated learning. Thirdly, the perceived ease of use and the expectation of confirmation by students has indirectly affects continued intention through perceived usefulness, satisfaction and attitude of online self-regulated learning
\end{abstract}

Keywords-College student; online self-regulated learning; Expectation Confirmation Model; Technology Acceptance Model; Continued Intention

\section{INTRODUCTION}

In January 2017, China Internet Network Information Center (CNNIC) released its 39th Statistical Report on Internet Development in China. According to the report, as of December 2016, there are 138 million online education users in China, up 25\% over 2015, among which 97.98 million are via mobile phones, up 84.8\% from 2015 (CNNIC, 2017). Online education is a form of online self-regulated learning. Therefore, to some extent, it can be seen that online selfregulated learning has gradually received favor. From another aspect, CNNIC's report also reveals that student has become the largest group among netzines, accounting for a proportion of $25 \%$. With the ever-changing study and life-style of students, especially college students, self-regulated learning in the context of Internet has become a major way of learning.

Online self-regulated learning is viewed as learning actions through Internet decided by learners. With the rapid development of network and new media technology, online self-regulated learning is featured with rich learning resources, diversified learning communication tools, and learners' independency and initiative (Pan, 2012). In the process of elearning, learners are not restricted to only one kind of learning tool, for example E-learning platform or MOOC. Instead, they have different online learning tools to access various learning resources. In such a context, learners much self-regulate, self-adjust and effectively evaluate these resources and tools. Therefore, these evaluations will have direct or indirect effect on their continued intention of using such way of learning.

From the perspective of Information System (IS), online self-regulated learning is an application of IS, learners adopting different information systems in learning. Bhattacherjee (2001) believes that users' effective continuance behavior is a major way to realize the value of IS. Therefore, whether college students can continue self-regulated learning by using different e-learning tools and realize the value of online self-regulated learning has become the point of concern.

Expectation Confirmation Model (ECM) has been widely acetated and applied. However, some researchers raised that ECM is insufficient to explain users' continuance intention. For better studying users' continuance intention, ECM theoretical model needs to be extended from different perspectives (Bhattacherjee and Barfar, 2001) (Lee, 2010). Therefore, based on ECM theory and integrated with Expectation Confirmation Theory (TAM), this paper constructs a theoretical model on the influence factor of 
college students' continued intention of online self-learning, taking college students as empirical survey respondents and PLS for structural model analysis. This research discusses the influence factor of college students' continued intention of online self-regulated learning, aiming to analyze college students' motivation, reveal the key elements and function mechanism of students initiatively using network resources and tools for study, and providing theory guidance and suggestions for the further development of online selfregulated learning.

\section{LITERATURE REVIEW}

\section{A. Expectation-Confirmation Model}

Expectation-Confirmation Model (ECM) stems from Expectation Confirmation Theory (ECT) which is proposed by Oliver in 1980 (Oliver, 1980). ECT was firstly applied in studying consumer behavior, comparing consumers' expectation pre- and post-consumption to evaluate their satisfaction of products and services. Then, satisfaction becomes a reference of purchase and repurchase. Then, Bhattacherjee (2001) applied ECT into the research of IS continuance use and validated through Structural Equation Model, and obtained an ECM of IS, as shown in Fig. 1.

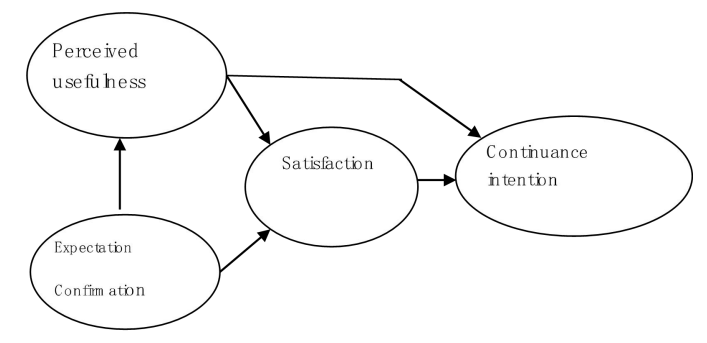

Fig. 1. Expectation-Confirmation Model of IS

Bhattacherjee (2001) found that perceived usefulness and satisfaction are the two major factors influencing users' continuance intention. Users' satisfaction is affected by perceived usefulness and expectation confirmation, while perceived usefulness is decided by expectation confirmation. This theory has been widely applied in researches across different subjects, such as e-commerce (Bhattacherjee, 2001), portal website (Lin, Wu and Tsai, 2005), SNS network (Yin and Yang, 2011), mobile network (Hong, Thong, and Tam, 2006), instant message (Wang, Ngai, and Wei, 2012), academic blogs (Wang and Gan, 2014) and etc.

In recent years, ECM has also been applied in studying elearning. Chen Meiling etc., (2014), considering correlation features, added two value variables, namely the perceived ease of use and perceived mobility, into ECM. Yang Zhengwen etc., (2015) integrated ECM with the features of digital education resources and studied the continuance use of digital education resource users. Li Wu and Zhao Xing (2016) integrated ECM with social characteristics and studied college students' continued intention of socialized reading APPs and its occurrence mechanism. They found that expectation confirmation, satisfaction and subjective norm formed while using socialized reading apps are the major factors influencing users' continuance use. Yang Genfu (2016) applied ECM and self-determine theory in studying the influence factor of MOOC's continuance use and found that perceived usefulness, satisfaction and internal motivation have obvious direct effect. Based on ECM, Limayem and Cheung (2008) believed that the relation between e-learning users' continued intention and continuance use is negatively associated with users' using habit.

Above literature indicates that although ECM has received wide recognition, most researches are the extensions of ECM with different subject features, aiming to better explaining users' continued using behavior. Bhattacherjee and Barfa (2011), based on the literature of ECM application, proposed that researchers should supplement ECM theory from different perspectives. Bhattacherjee and Lin (2015), integrating ECM theory, rational action theory and habit, discussed the continuance of IS from three complementary perspectives. Therefore, this paper extended ECM by integrating TAM, aiming to better explaining the continued behavior of college students on online self-regulated learning.

\section{B. Technology Acceptance Model (TAM)}

Davis (1989) proposed Technology Acceptance Model (TAM) based on the Theory of Reasoned Action (TRA). As a theoretical framework explaining users' acceptance process of IS, TAM has received wide recognition and is deemed with wider application range than TRA (Mathieson, 1991). Venkatesh and Davis (2000) believed that TAM is comparable to TRA and Theory of Planned Behavior (TPB). TAM emphasizes the intention of using technology from the perspective of attitude and indicates that perceived usefulness and ease of use will influence users' attitude to IS acceptance, and then the use intention. Perceived usefulness is decided by perceived ease of use, as shown in Fig. 2.

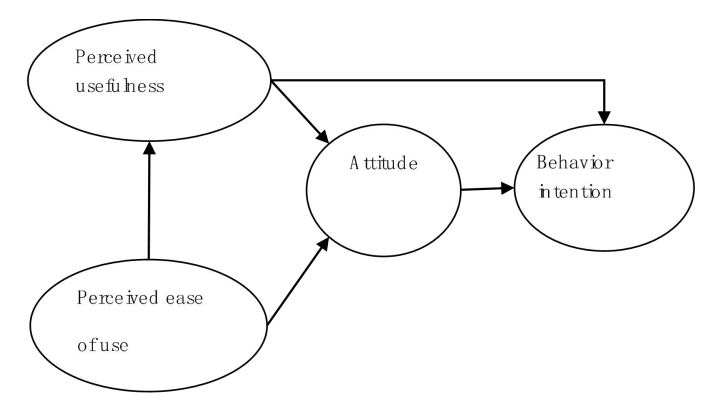

Fig. 2. Technology Acceptance Model (TAM)

TAM is mainly developed to predict users' initial acceptance of IS. However, many researches based on TAM connotate an assumption that continuance use is a extension of acceptance, and applied TAM in the context of postacceptance continuance use. These researches explained users' continued using behavior of IS via TAM (Karahanna, Straub, and Chervany, 1999) (Taylor and Todd, 1995).

Hong etc., (2006) proposed that TAM is applicable for not only users' acceptance behavior, but also continued using behavior. Some researchers also applied TAM in discussing 
other continued using behaviors related to e-learning, such as Roca and Gagné (2008) and Lee (2010) and Mohammadi (2015). Zhao Wanying (2016) also integrated TAM with social factors to discuss users' continued using behavior in mobile reading. These relevant researches has verified that TAM is effective in explaining users' continuance use. However, TAM is rarely applied to study the behavior of college students' online self-regulated learning. Therefore, this paper will integrate TAM and ECM to discuss this topic.

\section{RESEARCH MODEL AND HYPOTHESIS}

\section{A. Theoretical Model}

ECM of IS is easy and effective. However, many researchers regard that the explanation on users' continued intention only from expectation confirmation and perceived usefulness is insufficient. Considering TAM has been proved to be applicable in studying continued use behavior, this paper, integrating Bhattacherjee's ECM (2001) and Davis's TAM (1989), built a model studying college students' continued intention of online self-regulated learning, as shown in Fig. 3.

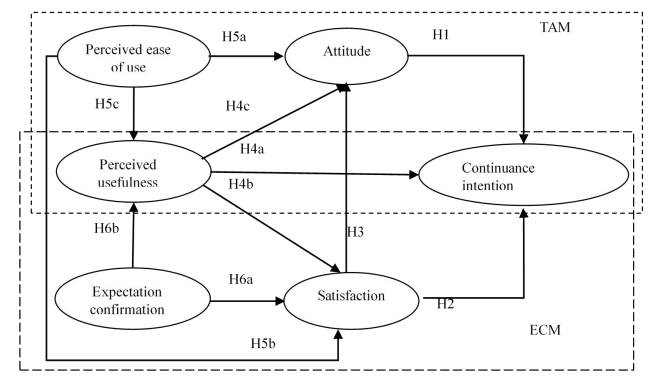

Fig. 3. The conceptual model of college students' continued intentions of online self-regulated learning

\section{B. Research hypothesis}

\section{1) Attitude and continued learning intention}

Continued intention of online self-regulated learning represents the situation that learners are willing of reparticipation based on their prior experience of online selflearning. Attitude refers to the positive and negative affect that user expressed to certain object or action (Fishbein and Ajzen, 1975), represented by users' positive, neutral, or negative evaluation and mental tendency to certain object, including product, service and behavior. Attitude is usually the results of prior experience (Roest and Pieters, 1997). In the context of online self-regulated learning, attitude is viewed as users' positive or negative mental tendency towards continued elearning, such as like or unlike, which is a behavior attitude.

Fishbein and Ajzen (1975) believed that the attitude towards behavior and behavior itself has direct association. The stronger the positive attitude one has towards certain action is, the stronger his/her behavior intention is. In TAM, users' attitude of IS will directly affect users' intention of use. Extensive studies on attitude and behavior have also verified the effect of positive attitude on action. Hence,
H1. Users' attitude towards continued use of online selfregulated learning is positively related with their continued use intention.

\section{2) Satisfaction and Continued Intention}

Satisfaction refers to the level that users demands are satisfied. Bhattacherjee (2001) defines satisfaction of IS as users' comprehensive feeling and evaluation following actual use, which is subjective. In this research, satisfaction is students' comprehensive feelings, satisfied or unsatisfied, towards the process of online self-regulated learning and other aspects.

In ECM of IS, continued use intention is mainly decided by the satisfaction of IS. Prior researches also indicate that satisfaction is an important indicator to predict the continued use intention of e-learning. This leads to the hypothesis:

H2. Users' satisfaction towards online self-regulated learning is positively associated with their continued intention of learning.

\section{3) Satisfaction and attitude}

As to the association between satisfaction and attitude, researches in marketing has proposed that consumers' satisfaction can promote their positive attitude or preference to the brand. Satisfaction, as an important post-consumption psychological state will affect consumers' attitude and preference. Burton etc., (2001) proposed that consumers' attitude is based on their prior experience and the satisfaction generated from external information.

In the context of online self-regulated learning, students' comprehensive feelings have direct effects on their attitudes. Satisfied process of online self-regulated learning will lead to positive attitude. Otherwise, unsatisfied process comes to negative attitudes. Hence:

H3. Users' satisfaction towards online self-regulated learning is positively associated with their continued intention of use.

4) Perceived usefulness with attitude, satisfaction and continued intention of use

In ECM, perceived usefulness puts more emphasis on the constant cognitive belief user accumulated after using the system. It is the potential value that users believe they can obtain from the system (Bhattacherjee, 2001). The value of usefulness is a kind of utilitarian mechanism, namely an external motivation mechanism. This value has significant influence on users' behavior and is the key factor influencing users' satisfaction (Dong, etc., 2010). Many researches has verified that perceived usefulness is a key motivation factor for the satisfaction level and continued intention of IS users (Hong, etc., 2006) (Yang, 2016) (Bhattacherjee, 2008). As to online self-regulated learning, perceived usefulness is reflected as learners' subjective assumption that e-learning can help them achieve learning targets and improve learning performance. If their learning performances are not improved after e-learning, users will have negative feelings and become unsatisfied, which will consecutively impact their continued intention. This leads to the hypothesis that: 
H4a. Users' perceived usefulness of online self-regulated learning is positively associated with their satisfaction.

H4b. Users' perceived usefulness of online self-regulated learning is positively associated with on their continued intention.

In the area of marketing, many researches has verified that consumers' attitude is affected by their perceived usefulness of product or services (Wolfinbarger and Gilly, 2003) (Yoo and Donthu, 2001), which is applicable to IS (Lederer etc., 2000) (Moon and Kim, 2001) (Vijayasarathy, 2004). These researches also reveal that users' perceived usefulness of online self-regulated learning will lead to positive attitude. Hence:

H4c. Users' perceived usefulness of online self-regulated learning is positively associated with their attitude.

5) Perceived ease of use, attitude and perceived usefulness

In TAM, perceived ease of use refers to the easy level user perceived while using certain IS (Davis, 1989). Many researches on behavioral decision and IS proposed that individuals are prone to make the easier choice when facing decision. This supports the association between users' perceived ease of use and emotional tendency. In other words, users' perceived ease of use is an important cognitive variable influencing users' affect (such as attitude and satisfaction) towards the IS (Davis, 1989) (Karahanna etc., 1999). The association between perceived ease of use, attitude and satisfaction is performed as a type of internal motivation mechanism (Davis etc., 1989). Rogers (1995) believed that users' perceived complexity of IS will lead to negative affect, for example resistance, especially under voluntary situation. Self-regulated learning in essence is more of a voluntary behavior.

In this research, perceived ease of use refers to the degree of ease users felt during online self-regulated learning. Students use different APPs or platforms which need different technical operations, such as search information, communication, questioning, evaluation and etc. If students feel it is easy to use these apps or platforms, they will generate a cognitive and emotional tendency as positive attitude and satisfaction. Hence:

H5a. Users' perceived ease of use during online selfregulated learning is positively associated with their continued intention.
H5b. Users' perceived ease of use during online selfregulated learning is positively associated with their satisfaction.

Meanwhile, the easier students feel for e-learning, the higher learning efficiency they obtain. With the same efforts, students with easier perception will have higher performance, which coincides with the direct positive influence of users' perceived ease of use on their perceived usefulness in TAM. Hence:

$\mathrm{H} 5 \mathrm{c}$. Users' perceived ease of use in online self-regulated learning is positively associated with their continued intention.

6) Expectation confirmation, perceived usefulness and satisfaction

Expectation confirmation refers to users' expectation and confirmation degree pre- and post-using IS (Bhattacherjee, 2001). The higher the expectation-confirmation degree users have to IS, the higher their perceived usefulness and satisfaction will be (Bhattacherjee, 2001). In the context of college students' online self-regulated learning, the learning source will provide the learners repetitive feedback, through which learners can evaluate their behavior of e-learning. In other words, learners hold certain expectations to online selfregulated learning based on their experience on life and study in the first place. After actual learning, if the receiving exceeds their expectation, namely high expectation-confirmation degree, learners will feel and acknowledge its usefulness. Hence:

H6a. Users' expectation confirmation degree of online self-regulated learning is positively associated with their satisfaction.

H6a. Users' expectation confirmation degree of online self-regulated learning is positively associated with their perceived usefulness.

\section{QUESTIONNAIRE AND DATA COLLECTION}

\section{A. Questionnaire}

Four variables were measure in this study: perceived usefulness, perceived ease of use, expectation confirmation, attitude, satisfaction and continued intention. All these variables were measured using multiple-item scale, drawn from the classical literature in relevant area and adapted to the specific context in this study. 7-Likert scale is applied to evaluate all the variables, anchored between "strongly disagree" to "strongly agree". The measurement of each variable is shown in Table 1.

TABLE I. MEASUREMENT OF VARIABLES

\begin{tabular}{|c|c|c|c|}
\hline Variable & Code & Operational Definition & Literature \\
\hline \multirow{3}{*}{$\begin{array}{l}\text { Perceived Usefulness } \\
\text { (PU) }\end{array}$} & PU1 & Online self-regulated learning can help improve my study capability. & \multirow[t]{3}{*}{ Bhattacherjee (2001) } \\
\hline & PU2 & Online self-regulated learning can help me learn more knowledge. & \\
\hline & PU3 & Online self-regulated learning is very useful to my study. & \\
\hline \multirow{3}{*}{$\begin{array}{l}\text { Perceived ease of use } \\
\text { (PEOU) }\end{array}$} & PEOU1 & Online self-regulated learning is easy. & \multirow{3}{*}{ Davis (1989) } \\
\hline & PEOU2 & Online self-regulated learning is easy to operate. & \\
\hline & PEOU3 & Online self-regulated learning is not a challenge. & \\
\hline
\end{tabular}




\begin{tabular}{|c|c|c|c|}
\hline \multicolumn{4}{|c|}{ Cont. to TABLE I } \\
\hline \multirow{3}{*}{$\begin{array}{l}\text { Attitude } \\
\text { (ATTI) }\end{array}$} & ATT1 & I like to learn through Internet. & \multirow[t]{3}{*}{ O'cass and Carlson (2010) } \\
\hline & ATT2 & Online self-regulated learning is something makes me happy. & \\
\hline & ATT3 & Online self-regulated learning is a wise choice. & \\
\hline \multirow{3}{*}{$\begin{array}{l}\text { Expectation Confirmation } \\
\text { (CON) }\end{array}$} & CON1 & Online self-regulated learning is better than my expectation. & \multirow{3}{*}{$\begin{array}{l}\text { Bhattacherjee (2001) } \\
\text { Lee (2010) }\end{array}$} \\
\hline & CON2 & The performance of online self-regulated learning is better than my expectation. & \\
\hline & CON3 & The result of online self-regulated learning exceeds my expectation. & \\
\hline \multirow{4}{*}{$\begin{array}{l}\text { Satisfaction } \\
\quad \text { (SAT) }\end{array}$} & SAT1 & I am satisfied with online self-regulated learning. & \multirow[t]{4}{*}{ Bhattacherjee (2001) } \\
\hline & SAT2 & I am satisfied with the results of online self-regulated learning. & \\
\hline & SAT3 & I am satisfied with my general affect about online self-regulated learning. & \\
\hline & SAT4 & I am satisfied with the general experience of online self-regulated learning. & \\
\hline \multirow{3}{*}{$\begin{array}{l}\text { Continued Intention } \\
\text { (CI) }\end{array}$} & CI1 & I will continue online self-regulated learning. & \multirow[t]{3}{*}{ Bhattacherjee (2001) } \\
\hline & $\mathrm{CI} 2$ & I will take online self-regulated learning as a usual way of learning. & \\
\hline & $\mathrm{CI} 3$ & I decided to continue online self-regulated learning. & \\
\hline
\end{tabular}

\section{B. Data collection}

Data was collected via a questionnaire. The survey respondents were undergraduate students randomly selected from one university. 230 questionnaires were sent out with 227 collected back. As this research is focused on the continued behavior of online self-regulated learning, to guarantee that the research samples have certain experience with e-learning, a question about the ratio of e-learning time to Internet surfing time is added into the questionnaire. ${ }^{1}$ If " $<1 / 8$ " is selected, it can be deemed that this sample rarely takes elearning, which should be deleted in model analysis. It turns out that there are 60 students select " $<1 / 8$ ". Therefore, 167 effective samples are obtained, with an effective rate of $72.6 \%$. Among them, 37\% are male and $63 \%$ are female.

\section{DATA ANALYSIS}

Data was analyzed via SmartPLS 3.00 because (1) PLS does not have strict requirements on normal assumption; (2) it does not require large sample points; (3) it combines confirmatory factor analysis and linear regression, and can operate measurement model and structural model at the same time. To ensure the stability of analysis results, this research adopts the widely recommended Monte Carlo analysis (Marcoulides and Saunders, 2006), namely using bootstrapping to analyze data. Model verification is divided into two steps: first is measurement model verification, including verifying the questionnaire's reliability and validity; second is structural model verification, namely verifying hypothesis.

\section{A. Reliability and validity verification}

Reliability analysis can be verified via the internal consistency coefficient, Cronbach' ${ }^{\alpha}$. According to Nunnally and Bernstein (Nunnally and Bernstein, 1994), when Cronbach' $\alpha>0.7$, reliability is acceptable. As tested, the Cronbach' $\alpha$ of all major variables are above 0.7 , which means that the questionnaire has good internal consistency and its reliability is acceptable.

Convergent validity can be evaluated via Composite Reliability (CR), Average Variance Extracted (AVE) and Factor Loading suggested by Fornell and Larcker (1981). CR should exceed 0.7, AVE should exceed 0.5 and factor loading should exceed 0.7 , then the convergent validity of variables is high. From Table 2, all the variables have CR values over 0.85 , AVE over 0.65 , and factor loading over 0.7 , which means that all the variables have good convergent validity.

Discriminant validity can be evaluated via comparing AVE's square root with variable correlation coefficient. According to Fornell and Larcker (1981), AVE's square root should exceed the correlation coefficient of that and other variables. As shown in Table 2, AVE's square root of all the variables exceed their correlation coefficients, indicating that the measurement model in this research has good discriminant validity.

TABLE II. RELIABILITY ANALYSIS AND CORRELATION COEFFICIENT

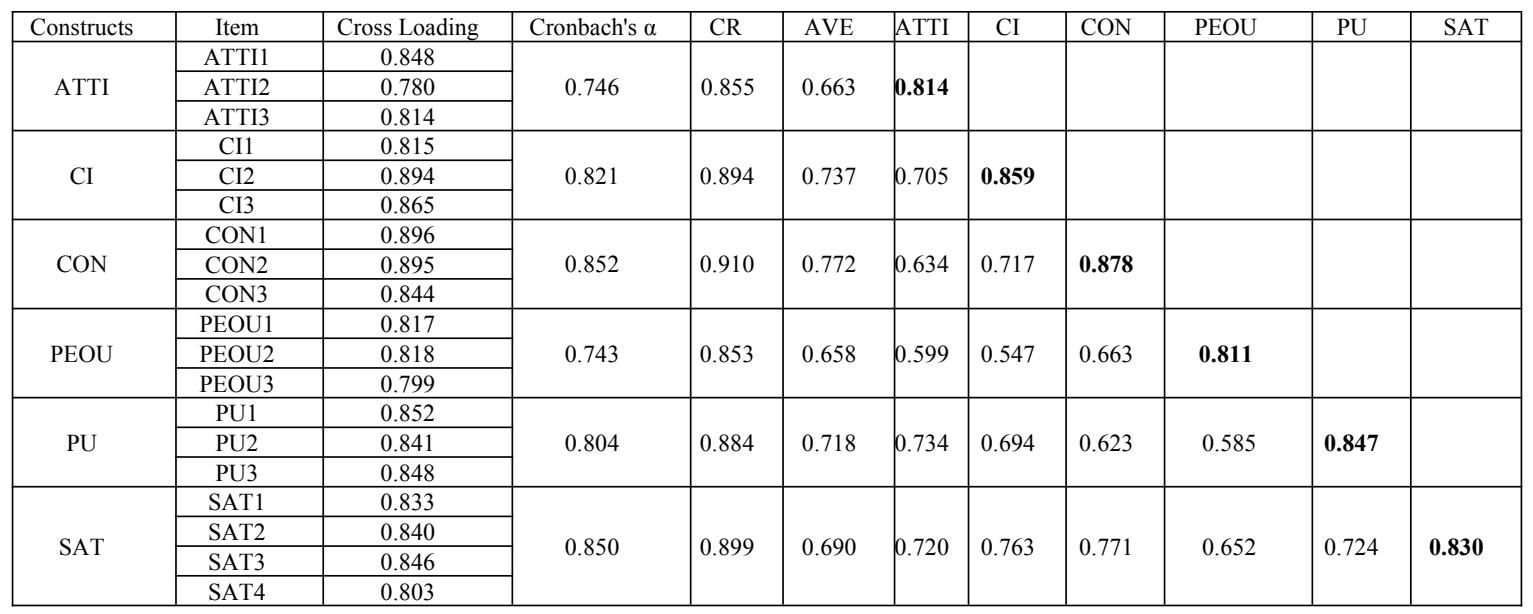

1 What's the ratio of e-learning time to your Internet surfing time?

A. $<1 / 8$,B. $1 / 8-1 / 4$, C. $1 / 4-1 / 2$,D. about $1 / 2$,E. above $1 / 2$ 
Legend: $\quad$ ATTI $=$ Attitude, $\quad \mathrm{CI}=$ Continued Intention, $\mathrm{CON}=$ Expectation Confirmation, $\mathrm{PEOU}=$ Perceived ease of use, $\mathrm{PU}=$ Perceived usefulness, $\mathrm{SAT}=$ satisfaction. Diagonal bold=AVE's square root

\section{B. Structural model verification}

variance (R2) is jointly explained by path coefficient and variables via Smart PLS, as shown in Fig. 4. The result of model verification shows that all the hypothesis proposed in this research are supported.

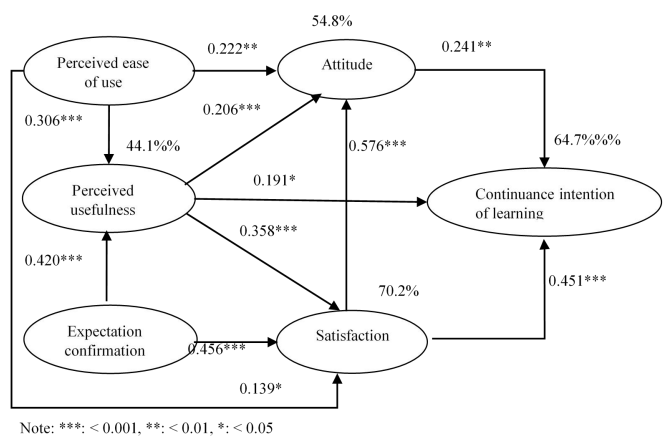

Fig. 4. Model verification result of college students continued intention on online self-regulated learning

As to variable explaining variance, perceived usefulness, attitude and satisfaction explained $64.7 \%$ of the variances; perceived usefulness, perceived ease of use and satisfaction jointly explained $54.8 \%$ of attitudes; perceived usefulness, perceived ease of use and expectation confirmation jointly explained $70.2 \%$ of satisfaction; and perceived ease of use and expectation confirmation explained $44.1 \%$ of perceived usefulness.

\section{Effectiveness Evaluation}

To further understand the real influence of independent variables on dependent variables, path coefficient is adopted to calculate the direct, indirect, and total effectiveness of independent variables on dependent variables. The total effect value is a sum of direct effect value and indirect effect value (Qiu, 2013). For example, in this research the direct effect value of satisfaction on continuance intention is 0.449 . Meanwhile, satisfaction has indirect influence on continuance intention through attitude, with its effect value $0.576 * 0.241=0.138$ and total effect value $0.449+0.138=0.587$. The total effect value of independent values on dependent values are shown in Table 3 .

TABLE III. TOTAL EFFECT VALUE

\begin{tabular}{|l|l|l|l|l|}
\hline Variable & ATTI & CI & PU & SAT \\
\hline ATTI & & 0.241 & & \\
\hline CON & 0.349 & 0.438 & 0.420 & 0.606 \\
\hline PEOU & 0.366 & 0.259 & 0.306 & 0.249 \\
\hline PU & 0.206 & 0.403 & & 0.358 \\
\hline SAT & 0.576 & 0.587 & & \\
\hline
\end{tabular}

\section{CONCLUSIONS, SIGNIFICANCE AND IMPLICATIONS}

\section{A. Conclusions and Significance}

Based on the literature and theoretical analysis about users' behavior, this paper integrated ECM with TAM and built a structural model studying college students' continuance intention of online self-regulated learning. Structural equation model is applied for empirical verification. The explanation degree of this model is $64.7 \%$. This research not only verified ECM and TAM in online self-regulated learning context, but also found that TAM performs well in explaining the continuance intention of e-learning. The effective integration of ECM and TAM effectively improved the explanation degree on the continuance intention of e-learning and received deeper understanding on the influence mechanism between variables. Based on the theory of ECM and TAM, this research found that perceived ease of use can indirectly influence students' continued learning intention via satisfaction, while perceived usefulness can indirectly influence students' continued learning intention via attitude. Besides, students' attitude towards e-learning can be influenced by their prior experience and comprehensive evaluation.

\section{1) Continuance intention of online self-regulated learning}

Satisfaction $(\beta=0.451, \mathrm{p}<0.000)$, perceived usefulness $(\beta=0.191, p<0.05)$ and attitude $(\beta=0.241, p<0.001)$ have direct and significant positive influence on continued learning intention. From path coefficient, satisfaction has the largest direct influence on the continuance intention of leaning, followed by attitude and perceived usefulness. This further verified that attitude, as a kind of post-behavior tendency and preference of users, is still an important factor influencing users' continuance intention of online self-regulated learning.

Besides, perceived usefulness can generate direct influence on continued learning intention via attitude and satisfaction. From total effect value, the effect of satisfaction, perceived usefulness and attitude to continuance intention is $0.587,0.438$ and 0.241 respectively. The total effects of both satisfaction and perceived usefulness are larger than that of attitude. This verifies the assumption of ECM that satisfaction and perceived usefulness are the most important factor influencing continuance intention. Expectation confirmation and perceived ease of use can also generate indirect influence on continuance intention via perceived usefulness, attitude and satisfaction, with their indirect effect value of 0.438 and 0.259 respectively.

Above all, among the influencing factors of college students' continuance intention on e-learning, satisfaction, attitude and perceived usefulness all have direct and significant positive influence, among which perceived usefulness can also generate indirect influence. Besides, expectation confirmation and perceived ease of use can also generate indirect influence on continued learning. The total effect value ranging from the largest to the smallest are satisfaction, expectation confirmation, perceived usefulness, perceived ease of use and attitude. All of them jointly explain $64.7 \%$ of online self-regulated learning. Therefore, in a totally self-regulated learning context, to improve college students' internal motivation (satisfaction and attitude) and external 
motivation (perceived usefulness) can both directly promote continued intention of online self-regulated learning, while the improvement of perceived ease of use and expectation confirmation has indirect influence.

\section{2) Satisfaction of online self-regulated learning}

Perceived usefulness, expectation confirmation and perceived ease of use all have significant positive influence on the satisfaction of online self-regulated learning. Among them, perceived usefulness $(\beta=0.358, p<0.000)$ has direct significant influence. Besides direct influence, expectation confirmation and perceived ease of use can also generate indirect influence via perceived usefulness, with total effect values of 0.606 and 0.249 respectively. Therefore, the influence of expectation confirmation on satisfaction is higher than that of perceived usefulness and perceived ease of use, which is explaining $70.2 \%$ of online self-regulated learning. Therefore, to improve college students' perceived usefulness, perceived ease of use and expectation confirmation during e-learning can improve their satisfaction degree.

\section{3) Attitude of online self-regulated learning}

College students' perceived ease of use, perceived usefulness and satisfaction during online self-regulated learning all have significant positive influence. Perceived usefulness $(\beta=0.206, p<0.000)$ and satisfaction $(\beta=0.576, p$ $<0.000$ ) has direct influence on online self-regulated learning, while perceived ease of use not only generates direct influence $(\beta=0.222, p<0.01)$, but also indirect influence $(\beta=0.143$, $p$ $<0.001)$ via perceived usefulness and satisfaction with a total effect value of 0.366 . Besides, $54.8 \%$ of the attitude of online self-regulated learning can be jointly explained. Therefore, this research find that college students will do post-learning evaluation of this study method, including usefulness, ease of use and satisfaction, which will constantly impact their attitude towards e-learning. And in the context of selfregulated learning, the internal motivation emotion (satisfaction and perceived ease of use) have more significant influence on students' preference.

\section{4) Perceived usefulness of online self-regulated learning}

Students' perceived ease of use $(\beta=0.306, p<0.001)$ and expectation confirmation $(\beta=0.420, p<0.001)$ of online selfregulated learning will generate significant and direct positive influence on their perceived usefulness with R2 equals $44.1 \%$. This means that $44.1 \%$ change of the perceived usefulness of online self-regulated learning can be jointly predicted by perceived ease of use and expectation confirmation. Therefore, for the continuance of e-learning, perceived ease of use still has important impact on college students' perceived usefulness even though they have prior experience. Therefore, to improve college students' perceived usefulness to online self-regulated learning, perceived ease of use and expectation confirmation should be drawn attention to.

5) Expectation confirmation and perceived ease of use of online self-regulated learning

Based on the above analysis, college students' expectation confirmation and perceived ease of use towards online selfregulated learning has indirect influence on their continuance intention and direct influence on perceived usefulness, attitude and satisfaction. Among them, the impact of expectation confirmation is larger than that of perceived ease of use. Therefore, to improve college students' continuance intention of e-learning, coinciding with Bhattacherjee's (2001) research results, expectation confirmation still has important indirect influence.

\section{B. Research significance}

For theoretical significance, this research integrated ECM and TAM, the two classical theoretical models of IS usage behavior, further verified the adaptation of ECM, and found that TAM can explain users' continued using behavior. As different theoretical models stem from different viewpoints, rational and effective integration of different views can not only improve the explanation degree of research model, but also obtain some new findings. For example, in this research, variable Attitude is found to be an important influencing factor of continued learning intention. Meanwhile, attitude can be influenced by perceived usefulness and satisfaction. In continued behavior, attitude will be more likely influenced by the post-actual-experience evaluation. After taking online selfregulated learning, college students have clearer evaluation on perceived usefulness and satisfaction, and then change their attitudes to online self-regulated learning.

For practical significance, this research reflects that college students' internal and external motivations towards online self-regulated learning both have effects on their continued intention of e-learning. From the perspective of perceived ease of use, convenient Internet access, rich learning resources, and easy operation can help students realize fast and effective elearning; as to perceived usefulness, improving the diversity and quality of learning resources and providing a platform for study communication can let students have real effectiveness; from the perspective of expectation confirmation, to improve students' self-efficiency of e-learning can make sure that students obtain correct expectations and evaluations. Then, all these will promote students' positive attitude and satisfaction to online self-regulated learning and improve their continuance.

\section{Future expectation}

In future studies, we should first draw on the research theory and results from other subjects, and verify and integrate them for further findings; secondly, the antecedent variables of perceived usefulness, perceived ease of use, and attitude should be further discussed. For example, Yang Wenzheng etc., (2015) have proposed that the quality of resource, system and service have effect on users' perceived usefulness and expectation confirmation; thirdly, this research only discussed the continuance intention of online self-regulated learning. As some researchers have find that intention does not equal to actual behavior, for example Zhao Yang and Gao Ting (2015) has proposed that habit can adjust the association between intention and actual behavior, continued behaviors should be further discussed; fourthly, some researchers have proposed that college students' of different genders possess different attitudes and learning methods of online self-regulated learning. Therefore, future studies can introduce some characteristics of students, such as gender, age, major, 
character and so on, and discuss the influences of these characters.

\section{ACKNOWLEDGMENT}

This research was supported by the National Natural Science Foundation of China under Grant, 71402159,71162005,71362016, Yunnan Science and Technology Fund (2014FB116, 2017FA034), Educational and Teaching Reform Fund of Yunnan University, Yunnan Provincial E-Business Entrepreneur Innovation Interactive Space (2017DS012) \& Yunnan Provincial E-Business Innovation and Entrepreneurship Key Laboratory of colleges and universities (YES 2014 [16]).

\section{REFERENCES}

[1] China Internet Network Information Center (CNNIC). 39th Statistical Report on Internet Development in China [R]. 2017.(in Chinese)

[2] Bhattacherjee A. Understanding information systems continuance: An expectation-confirmation model[J]. MIS Quarterly, 2001, 25(3): 351370.

[3] Bhattacherjee A, Barfar A. Information technology continuance research: Current state and future directions[J]. Asia Pacific Journal of Information Systems, 2011, 21.

[4] Lee M-C. Explaining and predicting users' continuance intention toward e-learning: An extension of the expectation-confirmation model[J]. Computers \& Education, 2010, 54(2): 506-516.

[5] Oliver R L. A Cognitive Model of the Antecedents and Consequences of Satisfaction Decisions[J]. Journal of Marketing Research (JMR), 1980, 17(4): 460-469.

[6] Bhattacherjee A. An empirical analysis of the antecedents of electronic commerce service continuance[J]. Decision Support Systems, 2001, 32(2): 201-214

[7] Lin $\mathrm{C} \mathrm{S}, \mathrm{Wu} \mathrm{S}$, Tsai $\mathrm{R}$ J. Integrating perceived playfulness into expectation-confirmation model for web portal context[J]. Information \& Management, 2005, 42(5): 683-693.

[8] Hong S J, Thong J Y L, Tam K Y. Understanding continued information technology usage behavior: A comparison of three models in the context of mobile internet[J]. Decision Support Systems, 2006, 42(3): 18191834.

[9] Wang W, Ngai E W T, Wei H. Explaining Instant Messaging Continuance Intention: The Role of Personality[J]. International Journal of Human-Computer Interaction, 2012, 28(8): 500-510.

[10] Limayem M, Cheung C M K. Understanding information systems continuance: The case of Internet-based learning technologies $[\mathrm{J}]$. Information \& Management, 2008, 45(4): 227.

[11] Bhattacherjee A, Lin C-P. A unified model of IT continuance: three complementary perspectives and crossover effects[J]. European Journal of Information Systems, 2015, 24(4): 364-373.

[12] Davis F D. Perceived Usefulness, Perceived Ease of Use, and User Acceptance of Information Technology[J]. MIS Quarterly, 1989, 13(3): 319-340.

[13] Mathieson K. Predicting User Intentions: Comparing the Technology Acceptance Model with the Theory of Planned Behavior[J]. Information Systems Research, 1991, 2(3): 173-191.

[14] Venkatesh V, Davis F D. A Theoretical Extension of the Technology Acceptance Model: Four Longitudinal Field Studies[J]. Management Science, 2000, 46(2): 186

[15] Karahanna E, Straub D W, Chervany N L. Information technology adoption across time: A cross-sectional comparison of pre-adoption and post-adoption beliefs[J]. MIS Quarterly, 1999, 23(2): 183-213.
[16] Taylor S, Todd P. Assessing IT Usage: The Role of Prior Experience[J]. MIS Quarterly, 1995, 19(4): 561-570.

[17] Roca J C, Gagné M. Understanding e-learning continuance intention in the workplace: A self-determination theory perspective[J]. Computers in Human Behavior, 2008, 24(4): 1585-1604.

[18] Mohammadi H. Factors affecting the e-learning outcomes: An integration of TAM and IS success model[J]. Telematics \& Informatics, 2015, 32(4): 701-719.

[19] Fishbein M, Ajzen I. Belief, attitude, intention and behavior: An introduction to theory and research[D]. Addison - Wesley, 1975.

[20] Roest H, Pieters R. The nomological net of perceived service quality[J]. International Journal of Service Industry Management, 1997, 8(8): 336351

[21] Seddon P B. A Respecification and Extension of the DeLone and McLean Model of IS Success[J]. Information Systems Research, 1997, 8(3): 240.

[22] Bhattacherjee A, Perols J, Sanford C. INFORMATION TECHNOLOGY CONTINUANCE: A THEORETIC EXTENSION AND EMPIRICAL TEST[J]. Journal of Computer Information Systems, 2008, 49(1): 17-26.

[23] Islam A K M N. Investigating e-learning system usage outcomes in the university context[J]. Computers \& Education, 2013, 69(4): 387-399.

[24] Alraimi K M, Zo H, Ciganek A P. Understanding the MOOCs continuance: The role of openness and reputation[J]. Computers \& Education, 2015, 80: 28-38.

[25] Chiu C M, Hsu M H, Sun S Y, Lin T C, Sun P C. Usability, quality, value and e-learning continuance decisions[J]. Computers \& Education, 2005, 45(4): 399-416.

[26] Bolton R N. A Dynamic Model of the Duration of the Customer'S Relationship with a Continuous Service Provider: the Role of Satisfaction[J]. Marketing Science, 1998, 17(1): 45-65.

[27] O'cass A, Carlson J. Exploring the relationships between e - service quality, satisfaction, attitudes and behaviours in content - driven e service web sites[J]. Journal of Services Marketing, 2010, 24(2): 112127.

[28] Burton J, Easingwood C, Murphy J. Using qualitative research to refine service quality models[J]. Qualitative Market Research, 2001, 4(4): 217 223.

[29] Wolfinbarger M, Gilly M C. eTailQ: dimensionalizing, measuring and predicting etail quality[J]. Journal of Retailing, 2003, 79(3): 183-198.

[30] Yoo B, Donthu N. Developing a Scale to Measure the Perceived Quality of An Internet Shopping Site (SITEQUAL)[J]. Q J Electron Commer, 2001: 1--31.

[31] Lederer A L, Maupin D J, Sena M P, Zhuang Y. The technology acceptance model and the World Wide Web[J]. Decision Support Systems, 2000, 29(3): 269-282.

[32] Moon J W, Kim Y G. Extending the TAM for a World-Wide-Web context[J]. Information \& Management, 2001, 38(4): 217-230.

[33] Vijayasarathy L R. Predicting consumer intentions to use on-line shopping: the case for an augmented technology acceptance model[J], 2004, 41(6): 747-762.

[34] Davis F D, Bagozzi R P, Warshaw P R. User acceptance of computer technology: a comparison of two theoretical models[J]. Management Science, 1989, 35(8): 982-1003.

[35] Rogers E M. Diffusion of innovations[M]. Free Pr, 1995.

[36] Marcoulides G, Saunders C. Editor's Comments: PLS Modeling[J]. MIS Quarterly, 2006, 30(2): 3-9.

[37] Nunnally J C, Bernstein I H. Psychometric Theory[J]. American Educational Research Journal, 1994, 5(3).

[38] Fornell C, Larcker D F. Evaluating structural equation models with unobservable variables and measurement error[J]. Journal of marketing research, 1981, 18(1): 39-5 